\title{
Intravaginal and Menstrual Practices among Women Working in Food and Recreational Facilities in Mwanza, Tanzania: Implications for Microbicide Trials
}

\author{
Caroline F. Allen $\cdot$ Nicola Desmond $\cdot$ Betty Chiduo $\cdot$ \\ Lemmy Medard • Shelley S. Lees • Andrew Vallely • \\ Suzanna C. Francis • David A. Ross • Richard J. Hayes
}

Published online: 28 July 2010

(c) The Author(s) 2010. This article is published with open access at Springerlink.com

\begin{abstract}
Intravaginal and menstrual practices may potentially influence results of trials of microbicides for HIV prevention through effects on the vaginal environment and on adherence to microbicide and placebo products. As part of the feasibility study for the Microbicides Development Programme Phase 3 trial of a vaginal microbicide in Mwanza, a variety of quantitative and qualitative methods were used to describe these practices, associations with behaviour and underlying social norms among women working in food and recreational facilities. Intravaginal
\end{abstract}

A poster including some of the data was presented at the International Society for STD Research conference in 2007, as follows: Allen CF, Desmond NA, Chiduo B, Medard L, Lees SS, Vallely A, Hayes RJ, Ross DA (2007) Cleanliness, Sexuality and Microbicides: Vaginal Hygiene and Vaginal Substance Use in the Feasibility Study for the MDP Microbicides Trial in Mwanza, Tanzania. Poster presentation P-188, 17th Conference of the International Society for STD Research, Seattle, USA, July 29-August 1.

C. F. Allen $(\square) \cdot$ N. Desmond

Medical Research Council Social and Public Health Sciences

Unit, University of Glasgow, 4 Lilybank Gardens,

Glasgow G12 8RZ, UK

e-mail: allen.carolinef@gmail.com

N. Desmond · B. Chiduo · L. Medard · S. S. Lees ·

S. C. Francis

National Institute for Medical Research, Mwanza Centre,

Mwanza, Tanzania

S. S. Lees - A. Vallely - S. C. Francis - D. A. Ross - R. J. Hayes London School of Hygiene and Tropical Medicine, London, UK

A. Vallely

African Medical and Research Foundation, Mwanza, Tanzania cleansing by inserting fingers and either water alone or soap and water was thought necessary to remove "uchafu" (dirt), referring to vaginal secretions, including menstrual blood and post-coital discharge. Vaginal cleansing was carried out within 2 hours after $45 \%$ of sex acts. Sexual enhancement practices were less common. Intravaginal and menstrual practices and associated behaviours and demographic factors should be measured and monitored throughout microbicide trials to enable analyses of their impacts on microbicide effectiveness.

Keywords Africa - Vaginal practices · Women . HIV · Vaginal microbicides · Prevention of sexual transmission

\section{Introduction}

There is increasing research interest in intravaginal practices (IVP) and menstrual practices as possible risk factors for STI and HIV [1-6] and as potential influences on the results of trials of vaginal microbicides for HIV prevention [7-11]. In this paper we examine these practices among a group of women at high risk of HIV in Mwanza, Tanzania and discuss the implications for vaginal microbicide research and use. Microbicides are chemical or antiretroviral agents which may be applied genitally to prevent HIV transmission via sexual intercourse. Phase 3 trials of several candidate vaginal microbicides are in progress or have been completed [12]. These trials respond to the realisation of high and growing HIV incidence among women, particularly in developing countries [13], and that existing prevention strategies, such as condom use and partner reduction, are not feasible for 
many women, whose risk may derive mainly from male partner behaviour [14, 15].

IVP are said to include:

Intravaginal cleansing. Internal cleansing or washing inside the vagina. Includes wiping the internal genitalia with fingers or other substances... It also includes douching, which is the pressurised shooting or pumping of water or solution into the vagina.

Intravaginal insertion. Pushing or placing something inside the vagina (including powders, creams, herbs, tablets, sticks, stones, leaves, cotton, tampons, tissue etc.). [10]

Menstrual practices are also examined in this paper, and include intravaginal cleansing to remove blood, intravaginal insertion or external genital application of items to collect blood, and sexual activities during menstruation. These practices are important for the future of microbicides because they may be associated with microbicide acceptability or adherence, or have physical or biochemical impacts on the effectiveness of microbicides.

Intravaginal and menstrual practices are influenced by culturally grounded concepts of hygiene and sexuality, concepts which are also likely to influence the acceptability of microbicides inserted into the vagina to protect health and adherence to their use in trials. Influences on intravaginal and menstrual practices thus form part of the range of individual, partner/interpersonal, cultural and environmental factors which may impact on satisfaction with a microbicide product and willingness to use it [8, 9, 16-18]. It has been noted that inadequate adherence (correct and consistent use) may have affected the results of randomised controlled trials of some HIV prevention interventions including microbicides, and that there is a need for research to reveal influences on adherence [12, 19-22]. A further concern is that IVP and menstrual practices may result in removal or dilution of the microbicide product during trials, possibly resulting in underestimation of effectiveness. They may also alter the risk of HIV acquisition [3-6, 23], though randomisation and blinding should ensure that IVP are similar in both arms of microbicide trials.

During the feasibility study in preparation for the MDP301 Phase 3 trial of the PRO 2000 vaginal microbicide gel in Mwanza, Tanzania, we used a variety of quantitative and qualitative methods to explore the nature of intravaginal and menstrual practices and the social factors influencing them. This was part of a broader study of the social context affecting sexual behaviour in Mwanza prior to the introduction of microbicide and placebo gel in the trial [9]. The discussion draws out possible implications of our findings for acceptability, adherence and effectiveness of microbicides.

\section{Methods}

This was an integrated study, combining qualitative and quantitative methods. Participants were women in Mwanza City, Tanzania who worked in food or recreational facilities (FRF) (cooked food and local beer vending, bars, restaurants, guesthouses and hotels). Studies in Tanzania have shown women in these occupations are at high risk of HIV/STI [24-27]. Male customers of FRF were also included in the ethnographic research and focus group discussions. Table 1 shows the data collection methods, and how they complemented each other to seek a holistic understanding of intravaginal and menstrual practices and influences upon them.

Quantitative methods included the use of structured interview data to describe and identify factors associated with intravaginal and menstrual practices, and coital diary data to record the frequency of these practices. The methodology of the MDP feasibility study, including the structured enrolment interviews, has been detailed previously [27], as has the methodology for the coital diary study [22].

Data from structured enrolment interviews were analysed to describe IVP and menstrual practices and explore the associations of socio-demographic and behavioural factors with reporting of any occurrence over the past 3 months of IVP and sex during menstruation. Given the lack of previous quantitative research exploring factors associated with IVP and menstrual practices, our exploratory research examined a wide range, including age, education, occupation, religion, ethnicity, housing conditions, geographic mobility, drug and alcohol use, type of partnership(s), sexual behaviour and beliefs about HIV. Unadjusted odds ratios were calculated for variables that may be associated with IVP and menstrual practices. Only variables found to be significant at the $5 \%$ level in the bivariate analysis are presented in Tables 3 to 5 and were analysed using multivariate logistic regression, using a forward stepwise procedure, to identify factors independently associated with IVP or sex during menstruation. Interrelationships between variables were analysed using crosstabulations, the Chi-square statistic and bivariate logistic regression. Several interrelationships were found; only those relevant to explaining intravaginal and menstrual practices are reported here.

Qualitative methods included ethnographic research to gain a preliminary understanding of social and environmental factors influencing intravaginal and menstrual practices, open-ended interviews (OEIs) to collect information on vaginal hygiene practices and concepts, and focus group discussions (FGDs) to gain an understanding of intravaginal and menstrual practices and associated norms and influences (see Table 1). The methodology for 


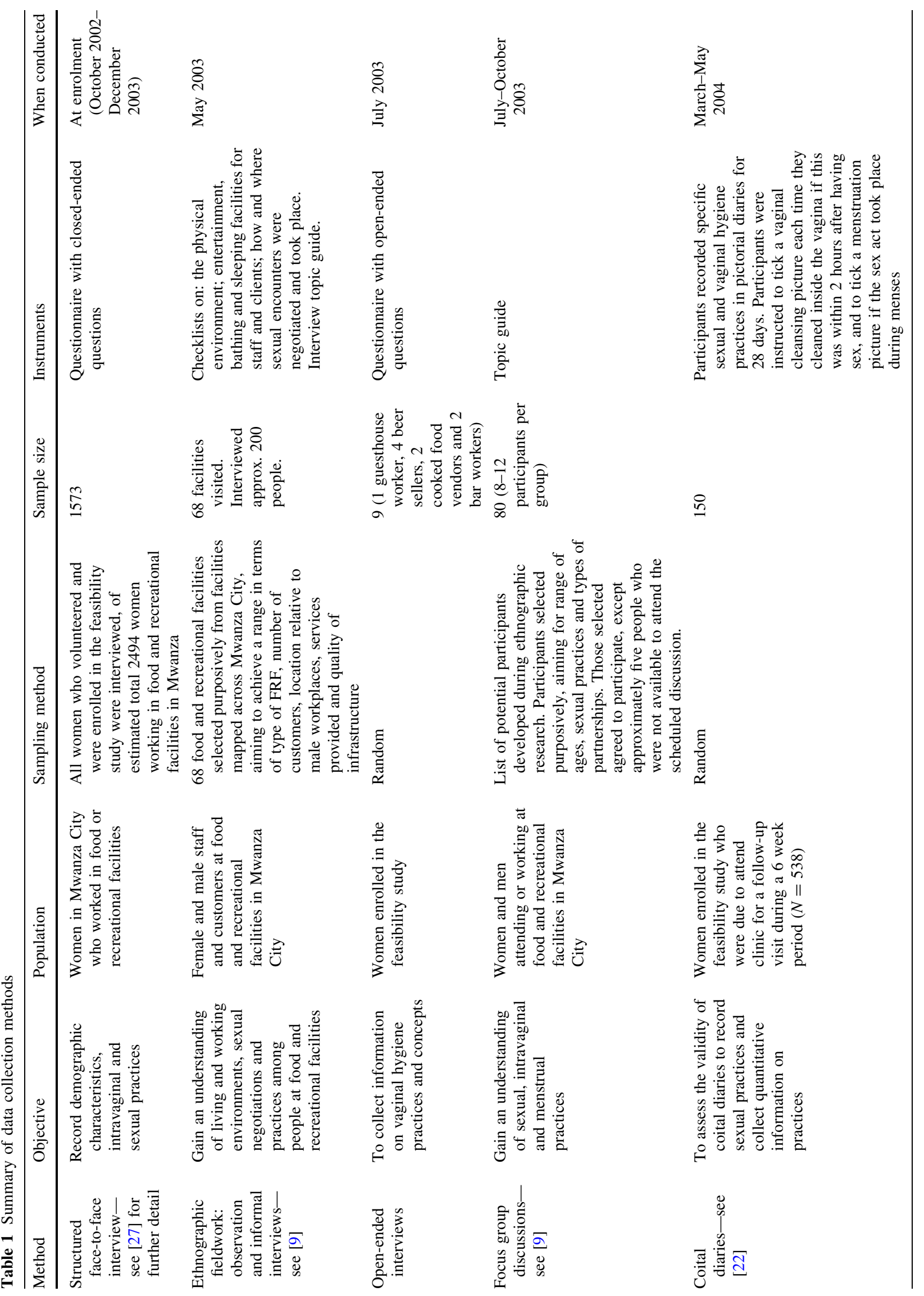


the ethnographic research and FGDs has been provided in more detail elsewhere [9].

Our FGDs grouped people according to sex and occupational category. Two FGDs were conducted with male customers of FRF. For the six female FGDs, occupations were grouped together because they shared similar sociodemographic profiles, working conditions and levels of HIV [27]. Three FGDs were conducted with cooked food and local beer vendors, who sell their food or beer from similar locations such as markets or at stalls at roadsides, by their homes or in shady spots. Two FGDs were conducted with bar, guesthouse and hotel workers who have in common that commercial sex often is negotiated or takes place at their work premises. One FGD was conducted with restaurant and grocery workers. A person of the same sex facilitated each discussion, which was tape-recorded.

All participants in enrolment interviews, OEIs, FGDs and the coital diary study provided written informed consent. During ethnographic research, information on the nature of the study was communicated to participants before informal interviews [28]. Quantitative data were analysed using SPSS 12 (SPSS, Chicago, Illinois, USA). Qualitative reports and FGD transcripts were written in Swahili and translated into English. Data were analysed using QSR-Nvivo 2.0 (QSR International, Australia), using a coding frame developed by the research team, supplemented as themes emerged. Data analysts checked their interpretations of the data with the field research team, sometimes going back to the Swahili documents for verification.

Ethics clearance was obtained from the National Medical Research Coordinating Committee in Tanzania and the London School of Hygiene and Tropical Medicine, UK.

\section{Results}

\section{Vaginal Hygiene}

In enrolment interviews, $74.6 \%$ of respondents reported cleansing inside the vagina over the past three months, with over $99 \%$ of these respondents saying they did this "for hygiene", $4.4 \%$ to avoid HIV/STI and $1.1 \%$ to avoid getting pregnant. Fingers were reportedly used to clean inside the vagina by $92.5 \%$ of those who cleansed. Water or water and soap were the most commonly reported substances for cleansing, each used by about half of respondents (Table 2).

Variables independently associated with reporting vaginal cleansing over the past 3 months included occupational group, ethnic group and religious affiliation. Vaginal cleansing was more likely if the respondent was a cooked food vendor or bar worker than in other occupational
Table 2 Percentages of respondents reporting intravaginal practices in enrolment interviews $(n=1573)$

\begin{tabular}{|c|c|}
\hline Intravaginal practice ${ }^{\mathrm{a}}$ & $\begin{array}{l}\text { Percentage practicing } \\
\text { this behaviour }\end{array}$ \\
\hline \multicolumn{2}{|l|}{ In the last 3 months, have you } \\
\hline $\begin{array}{l}\text { Dried your vagina to reduce lubrication } \\
\text { during sex? }\end{array}$ & 4.5 \\
\hline Wet your vagina before having sex? & 4.4 \\
\hline Had sex while you were menstruating? & 9.3 \\
\hline Cleaned inside your vagina? & 74.6 \\
\hline Why did you clean inside your vagina? & $\begin{array}{l}\text { Percentage of those } \\
\text { who cleaned inside } \\
\text { the vagina }(n=1174)\end{array}$ \\
\hline For hygiene & 99.7 \\
\hline To avoid getting pregnant & 1.1 \\
\hline To avoid getting HIV/STIs & 4.4 \\
\hline To have sex during menses & .7 \\
\hline Other & .5 \\
\hline \multicolumn{2}{|c|}{ What did you use to clean inside your vagina? } \\
\hline Water only & 51.2 \\
\hline Water and soap & 48.2 \\
\hline Traditional method & .8 \\
\hline Disinfectant & .7 \\
\hline Cloth & 6.5 \\
\hline Fingers & 92.5 \\
\hline Other & .7 \\
\hline \multicolumn{2}{|l|}{ When do you clean inside your vagina? } \\
\hline Before sex & 22.9 \\
\hline After sex & 41.3 \\
\hline During menses & 39.8 \\
\hline Other & 88.9 \\
\hline
\end{tabular}

\footnotetext{
${ }^{a}$ All questions in the first column had multiple answer options, i.e. participants could choose more than one response
}

groups and/or if the respondent was Muslim or had "other" religion as compared with Protestants and Catholics. Vaginal cleansing was also more likely to be reported if the respondent was married than if she was single. It was less likely if the respondent had spent a night away from home in the past three months. It was positively associated with the number of sex partners (Table 3). There were many interrelationships between variables; not all are reported here. Spending a night away from home was significantly more prevalent among women with more partners and those who were not married (not shown).

Figure 1 includes the coital diary pictures corresponding to male condom use, vaginal cleansing and sex during menstruation, and shows frequencies of these practices. In diaries, $52.9 \%$ of sexually active respondents reported any occurrence of cleansing the vagina within 2 hours after having sex in the 28-day period. Vaginal cleansing within 2 hours followed $44.7 \%$ of sex acts. Condoms were used 
Table 3 Factors significantly associated with reporting of any occurrence over the past 3 months of vaginal cleansing: unadjusted odds ratios and results of multivariate logistic regression

\begin{tabular}{|c|c|c|c|c|c|c|c|c|}
\hline Variable & $\mathbf{N}$ & $\begin{array}{r}\text { \% reporting } \\
\text { vaginal } \\
\text { cleansing }\end{array}$ & $\begin{array}{r}\text { Un- } \\
\text { adjusted } \\
\text { Odds Ratio }\end{array}$ & $95 \% \mathrm{CI}$ & $\mathbf{P}^{\mathbf{a}}$ & $\begin{array}{r}\text { Adjusted } \\
\text { Odds } \\
\text { Ratio } \\
\end{array}$ & $95 \%$ CI & $\mathbf{P}^{\mathbf{b}}$ \\
\hline FULL SAMPLE & 1573 & 74.6 & & & & & & \\
\hline Age group & & & & & .030 & & & \\
\hline$<20$ & 114 & 72.8 & 1 & & & & & \\
\hline $20-24$ & 355 & 69.3 & .84 & $.53-1.35$ & & & & \\
\hline $25-34$ & 710 & 75.4 & 1.1 & $.73-1.78$ & & & & \\
\hline $35+$ & 393 & 78.6 & 1.37 & $.85-2.22$ & & & & \\
\hline Facility type & & & & & $<.001$ & & & .001 \\
\hline Cooked food vending & 839 & 77.5 & 1 & & & 1 & & \\
\hline Bar & 204 & 80.4 & 1.19 & $.81-1.75$ & & 1.25 & $.82-1.91$ & \\
\hline Guesthouse/ hotel & 284 & 73.2 & .80 & $.58-1.08$ & & .91 & $.66-1.28$ & \\
\hline Local beer vending & 115 & 62.6 & .49 & $.32-.73$ & & .54 & $.35-.82$ & \\
\hline Grocery/ restaurant & 131 & 61.1 & .46 & $.31-.67$ & & .53 & $.35-.80$ & \\
\hline Marital status & & & & & .001 & & & .004 \\
\hline Married & 586 & 78.2 & 1 & & & 1 & & \\
\hline $\begin{array}{l}\text { Separated/ divorced/ } \\
\text { widowed }\end{array}$ & 665 & 75.2 & .85 & $.65-1.10$ & & .88 & $.66-1.19$ & \\
\hline Single & 322 & 67.2 & .57 & $.42-.77$ & & .58 & $.41-.82$ & \\
\hline $\begin{array}{l}\text { Highest level of } \\
\text { education }\end{array}$ & & & & & .033 & & & \\
\hline $\begin{array}{l}\text { Did not complete } \\
\text { primary }\end{array}$ & 376 & 76.3 & 1 & & & & & \\
\hline Primary & 1032 & 75.3 & .95 & $.72-1.25$ & & & & \\
\hline Secondary & 130 & 63.8 & .55 & $.36-.84$ & & & & \\
\hline Other & 35 & 77.1 & 1.05 & $.46-2.39$ & & & & \\
\hline Ethnic group & & & & & .003 & & & .002 \\
\hline Sukuma & 581 & 79.0 & 1 & & & 1 & & \\
\hline Haya & 193 & 78.2 & .96 & $.64-1.42$ & & 1.04 & $.69-1.57$ & \\
\hline Jita & 138 & 70.3 & .63 & $.42-.95$ & & .65 & $.42-1.01$ & \\
\hline Other & 661 & 70.7 & .64 & $.49-.83$ & & .62 & $.47-.81$ & \\
\hline Religion & & & & & $<.001$ & & & $<.001$ \\
\hline Muslim & 397 & 79.8 & 1 & & & 1 & & \\
\hline Protestant & 355 & 69.3 & .57 & $.41-.80$ & & .55 & $.39-.78$ & \\
\hline Catholic & 697 & 72.6 & .67 & $.50-.90$ & & .65 & $.48-.89$ & \\
\hline Others ${ }^{c}$ & 113 & 85.8 & 1.53 & $.85-2.74$ & & 1.52 & $.84-2.75$ & \\
\hline $\begin{array}{l}\text { Have you spent a } \\
\text { night away from } \\
\text { home in the past } 3 \\
\text { months? }\end{array}$ & & & & & .008 & & & .003 \\
\hline No & 1036 & 76.7 & 1 & & & 1 & & \\
\hline Yes & 537 & 70.6 & .73 & $.58-.92$ & & .69 & $.53-.88$ & \\
\hline $\begin{array}{l}\text { Number of } \\
\text { partners in past } 4 \\
\text { weeks }\end{array}$ & & & & & $.001^{\mathrm{d}}$ & & & $.005^{\mathrm{d}}$ \\
\hline No partners & 370 & 69.2 & 1 & & & 1 & & \\
\hline 1 partner & 993 & 75.2 & 1.35 & $1.04-1.76$ & & 1.23 & $.93-1.64$ & \\
\hline 2 partners & 163 & 80.4 & 1.82 & $1.17-2.85$ & & 1.78 & $1.11-2.85$ & \\
\hline 3 to 20 partners & 30 & 84.8 & 2.48 & $1.08-5.71$ & & 2.29 & $.96-5.48$ & \\
\hline
\end{tabular}

Shaded area indicates that this variable was not independently associated with vaginal cleansing

${ }^{a}$ Significance assessed multi-parameter Wald test

b Adjusted for all variables included in the table. Significance assessed using multi-parameter Wald test

c "Other" religion was not defined in the questionnaire but is likely to have included Christians who did not regard themselves as "Protestant" or "Catholic". It may also have included African religions involving ancestral beliefs and animistic rites

d Test for trend 


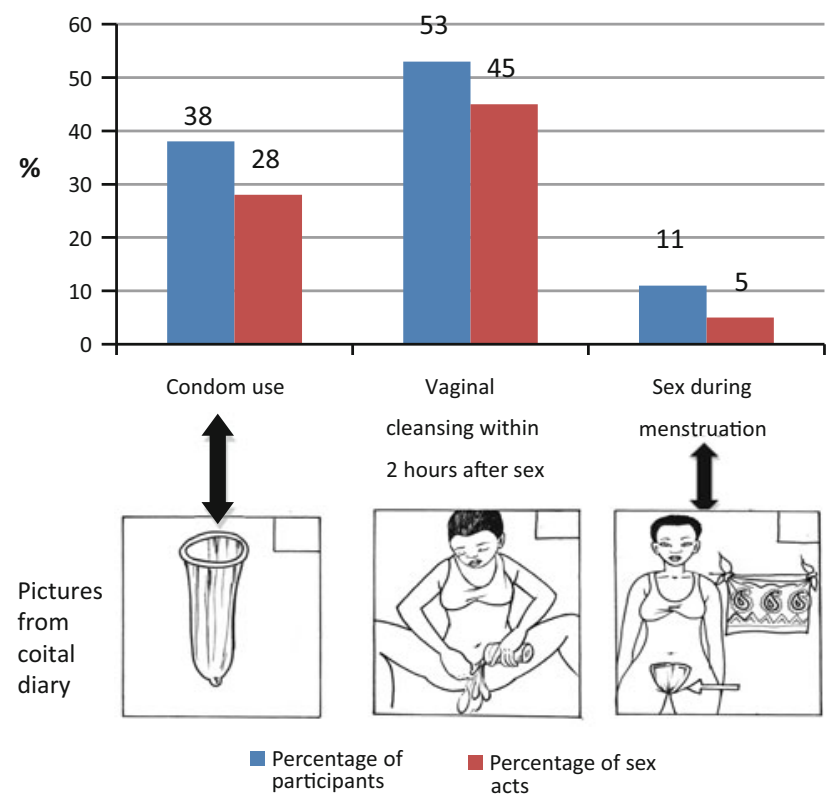

Fig. 1 Condom use, vaginal cleansing and sex during menstruation, over 28 days Note: this figure is based on data from the 141 coital diary study participants who reported any sexual activity over the 28 days of the study (of 150 study participants)

by $37.6 \%$ of sexually active women and in $27.9 \%$ of sex acts.

In qualitative research, vaginal cleansing was shown to be regarded as an essential component of personal hygiene. Respondents in FGDs, OEIs and ethnographic research used the Swahili word uchafu, meaning dirt, to refer to vaginal discharge generally, including menstrual blood and post-coital discharge. Women were expected to include intravaginal cleansing in their daily bathing routine and to increase the frequency before and after intercourse, during menstruation and in hot weather. These findings help interpret the result that $88.9 \%$ of structured interview respondents said that they cleansed at "other" times apart from or as well as before and after sex and during menses (Table 2). In enrolment interviews, respondents reported that they cleansed inside the vagina a median of 3 times a day (range 0-7).

Participants in OEIs and FGDs confirmed quantitative findings that finger-cleansing was the most commonly used method, with water and sometimes water and soap being inserted to remove "dirt". Cloth could be used to wipe the external and/or internal genitalia after sex, or to "suck and dry" inside the vagina after sex. There were no reports that women used devices to squirt liquid into the vagina (douching).

It was thought very important to cleanse the vagina before and after sex. Women were expected to present themselves to their partners "in a clean condition" for sex (FGD with males, FGD with bar and guesthouse/hotel workers, OEI with cooked food vendor). Sexual intercourse was thought to create heat, which created odour, and sperm also created a smell (OEIs with one bar worker and two cooked food vendors and FGDs with males and bar and guesthouse/hotel workers). Unless cleansing after sex took place, a woman's urine could smell bad and she might feel vaginal irritation (OEIs with guesthouse worker and cooked food vendor), or be afraid to sit near someone in case that person could smell them (OEI with guesthouse worker).

Vaginal cleansing was influenced by environmental factors such as water availability and the degree of privacy afforded by living arrangements. Most of the places women lived or worked did not have pipe-borne water, so some women kept a container with water in their bedrooms or nearby for vaginal cleansing. Women living in villages with water scarcity were thought to find it difficult to cleanse (OEIs with two cooked food vendors and ethnographic research), as were women who had casual sexual encounters outside, i.e. not in buildings. Cloths, including clothing, were often used to wipe the genital area when water was unavailable (FGD with restaurant and grocery workers and OEIs with a local brew vendor, a cooked food vendor and a bar worker). If a woman's house was fenced, cleansing using water was thought more likely since people would not see the woman going out to wash (OEIs with a local brew vendor and a cooked food vendor).

Women with long-term partners or husbands were not expected to cleanse the vagina immediately after sex every time. They could refrain from bathing immediately to avoid offending their partners by implying they were dirty or had STIs. During the day cleansing after sex was said generally to take place within 1 hour after sex (physical environment permitting), whereas at night women delayed thorough cleansing until the following morning, often just wiping the external genitalia with a cloth (OEI with a local brew vendor, FGD with cooked food vendors and ethnographic research). It was noted that going out to bathe every time after sex could be regarded as impractical and offensive:

You can't go outside and cleanse your vagina every time you finish having sex, it will just be a joke.

(quoted in interview notes from OEI with a local brew vendor)

For multiple acts of intercourse, cleansing the vagina every time was thought unlikely. Sex with casual partners was thought to carry a higher risk of infection, and women should aim to cleanse the vagina immediately after casual sex, regardless of timing. It was thought that women who exchanged sex for money would aim to cleanse the vagina after every encounter, partly in preparation for the next one (OEIs with a local beer vendor, a cooked food vendor and a bar worker). 
Menstrual Hygiene

Menstrual blood was viewed as one of the forms of "dirt" that should be removed during vaginal cleansing, using the methods outlined above. In an enrolment interview question, "What do you use during menstruation?", $60.2 \%$ reported using cloth, $14.8 \%$ sanitary napkins, $0.8 \%$ towelling material and $21.3 \%$ "other" (2.9\% did not respond). Nobody reported using tampons. While participants were not probed about intravaginal use, some focus group participants noted that cloth, cotton wool or toilet paper may be inserted into the vagina to absorb the blood (FGDs with cooked food vendors and bar and guesthouse/hotel workers). Others confirmed that cloth was most frequently used and noted that unless the cloth was properly washed, infection could result (FGD with bar and guesthouse workers).

\section{Sex during Menses}

In enrolment interviews, sex during menstruation during the past three months was reported by $9.3 \%$ of respondents. It was independently associated with literacy, rape, number of partners and mobility. It was more likely if the respondent reported a forced sexual encounter. It tended to be more likely as the number of partners increased. It was less likely if the respondent was not able to read. It was more likely among respondents who had spent more than a week away from home twice or more in the past three months as compared with those who had not spent a week away (Table 4). Number of sex partners was positively associated with indicators of mobility and forced sex and negatively associated with age. Literacy was not significantly associated with other variables included in the analysis.

In coital diaries, sex during menstruation was reported by $10.6 \%$ of respondents (roughly the same percentage of respondents as in enrolment interviews) and $14.0 \%$ of those who reported any sexual activity. Of sex acts in the past 28 days, $5.4 \%$, or 0.93 acts per woman, reportedly took place during menstruation (Fig. 1).

A variety of ills were thought to result from intercourse during menstruation, including stomach cramps, bleeding beyond the normal menstrual period, infertility, fungal infections and STI, including HIV infection (ethnographic research and two FGDs with bar and guesthouse workers). These were thought to be caused by the blood being pushed back into the womb:

It's very easy to get any disease if you have sex during menstruation. When you have sex with a man he pushes up the dirt and it will spread through your whole body.
(FGD with bar and guesthouse/hotel workers)

Blood is supposed to come out and when it goes back inside again it harms the uterus... Then the AIDS virus makes contact [with the uterus] and can penetrate it.

(FGD with food and local beer vendors)

Women were said to aim to avoid sex during menstruation whenever possible. However, some women, especially those who exchanged sex for money, reportedly did not always wait for their menses to stop. Some drank lemon juice, or squeezed lemon juice into the vagina, or took Aspirin tablets; methods believed to stop menstrual flow temporarily (one FGD with males, two FGDs with food and local beer vendors, two FGDs with bar and guesthouse workers and ethnographic research). Male coercion and fear of losing a male partner were thought by participants to account for many cases of sex during menstruation (ethnographic research and FGD with bar and guesthouse workers). However, participants in both male FGDs said they usually avoided sex during menstruation unless they had not had sex for a long time or were drunk.

\section{Practices to Enhance Sexual Pleasure}

In the past 3 months, $4.5 \%$ of enrolment interview respondents reportedly dried their vagina to reduce lubrication during sex, while $4.4 \%$ wetted their vagina before sex (Table 2). Reporting of vaginal drying was not significantly associated with socio-demographic and behavioural variables. Multivariate analysis showed the number of sex partners to be positively associated with vaginal wetting (Table 5). Having a commercial partner was positively related to number of sex partners.

Initially, when asked about things used to increase pleasure during sex, male focus group participants discussed female body parts and sexual responses, while female respondents mentioned experiences such as gentle touching, licking and sucking. Only on prompting did respondents mention substances that could be inserted into the vagina to increase pleasure, suggesting that these substances were not commonly used.

Respondents in every FGD, in ethnographic research and in two OEIs mentioned the intravaginal use of diluted or undiluted lemon juice to increase sexual pleasure, principally for males. This was thought to create the impression of narrowing the vagina. It was also thought to dry the vagina, though this was mentioned less frequently and did not seem to be the main objective.

When she squeezes lemon over the vagina, somehow it contracts. So when she gets a man its size is 
Table 4 Factors significantly associated with reporting of any occurrence over the past 3 months of sex during menstruation: unadjusted odds ratios and results of multivariate logistic regression

\begin{tabular}{|c|c|c|c|c|c|c|c|c|}
\hline Variable & $\mathbf{N}$ & $\begin{array}{l}\text { \% reporting } \\
\text { sex during } \\
\text { mens- } \\
\text { truation }\end{array}$ & $\begin{array}{r}\text { Un- } \\
\text { adjusted } \\
\text { Odds Ratio }\end{array}$ & $95 \% \mathrm{CI}$ & $\mathbf{P}^{\mathbf{a}}$ & $\begin{array}{r}\text { Adjusted } \\
\text { Odds } \\
\text { Ratio }\end{array}$ & $95 \% \mathrm{CI}$ & $\mathbf{P}^{\mathbf{c}}$ \\
\hline
\end{tabular}

\section{Age group}

$<20$

$20-24$

$25-34$

$35+$

Able to read a

letter or a

newspaper

Yes

No

\section{Number of places \\ lived in over past \\ year}

1 place

2 places

3 or more places

Number of years

working in this

facility

Less than 1 year

1 to 2 years

3 to 5 years

6 years or more

Number of times

spent more than 1

week away from

home in past 3

months

Did not spend more

than one week away

Once

Twice

3 or more times

Forced sex in the

past 3 months

No

Yes

1449

857

340

230

144

991

537

45

13.0

8.6

11.4

11.9

9.9

5.2

1
1.05
.85
.43

$.54-2.03$

$.45-1.60$

$.21-.89$

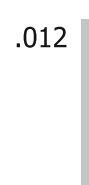

.028

.036

\section{1}

$.63 \quad .42-.95$
7.7

12.2

11.1

1.17-2.36

$.57-3.90$

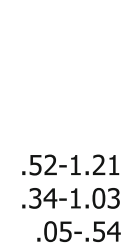

.008

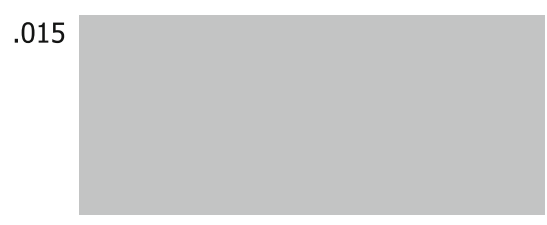

11.3
9.1
7.0
2.1

1
.79
.59
.17

.34-1.03

$\begin{array}{rrrr}1209 & 8.3 & 1 & \\ 255 & 9.5 & 1.15 & .72-1.84 \\ 59 & 18.6 & 2.52 & 1.27-5.01 \\ 44 & 22.7 & 3.24 & 1.55-6.74\end{array}$

1

$1.07 \quad .66-1.73$

$2.19 \quad 1.07-4.49$

$2.94 \quad 1.34-6.42$

$<.001$

.008

$\begin{array}{rrr}8.7 & 1 & \\ 19.3 & 2.52 & 1.51-4.19\end{array}$

1

$2.06 \quad 1.21-3.50$

\section{Number of sex}

partners in past 4

weeks

\begin{tabular}{lrrrrrr} 
No partners & 370 & 2.2 & .20 & $.10-.42$ & .21 & $.10-.45$ \\
1 partner & 993 & 10.2 & 1 & & 1.00 & $.90-2.37$ \\
2 partners & 163 & 15.3 & 1.60 & $1.00-2.57$ & 1.46 & .97 \\
3 to 20 partners & 46 & 26.1 & 3.12 & $1.56-6.21$ & 2.20 & $1.04-4.67$ \\
\hline
\end{tabular}

Shaded area indicates that this variable was not independently associated with sex during menstruation

${ }^{a}$ Significance assessed Wald test

b Test for trend

c Adjusted for all variables included in the table. Significance assessed using multi-parameter Wald test 
Table 5 Factors significantly associated with reporting of any occurrence over the past 3 months of vaginal wetting prior to sex: unadjusted odds ratios and results of stepwise multiple logistic regression analysis

\begin{tabular}{|c|c|c|c|c|c|c|c|c|}
\hline Variable & $\mathbf{N}$ & $\begin{array}{r}\% \text { reporting } \\
\text { vaginal } \\
\text { wetting }\end{array}$ & $\begin{array}{r}\text { Un- } \\
\text { adjusted } \\
\text { Odds Ratio }\end{array}$ & $95 \% \mathrm{CI}$ & $\mathbf{P}^{\mathbf{a}}$ & $\begin{array}{r}\text { Adjusted } \\
\text { Odds } \\
\text { Ratio } \\
\end{array}$ & $95 \% \mathrm{CI}$ & $\mathbf{P}^{\mathrm{c}}$ \\
\hline FULL SAMPLE & 1573 & 4.4 & & & & & & \\
\hline $\begin{array}{l}\text { Had a commercial } \\
\text { partner in past } 4 \\
\text { weeks }\end{array}$ & & & & & .021 & & & \\
\hline No & 1091 & 4.1 & 1 & & & & & \\
\hline Yes & 55 & 10.9 & 2.89 & $1.18-7.11$ & & & & \\
\hline $\begin{array}{l}\text { Number of sex } \\
\text { partners in past } 4 \\
\text { weeks }\end{array}$ & & & & & $<.001^{\mathrm{b}}$ & & & $<.001^{\mathrm{b}}$ \\
\hline No partners & 370 & 1.4 & .28 & $.11-.72$ & & .22 & $.07-.73$ & \\
\hline 1 partner & 993 & 4.7 & 1 & & & 1 & & \\
\hline 2 partners & 163 & 4.9 & 1.04 & $.48-2.24$ & & 1.10 & $0.45-2.67$ & \\
\hline 3 to 20 partners & 46 & 17.4 & 4.23 & $1.87-9.58$ & & 5.15 & $\begin{array}{r}1.97- \\
13.46\end{array}$ & \\
\hline
\end{tabular}

Shaded area indicates that this variable was not independently associated with vaginal wetting prior to sex

a Significance assessed Wald test

b Test for trend

c Adjusted for both variables included in the table. Significance assessed using multi-parameter Wald test

reduced, even wetness is reduced... In fact most men prefer tight vaginas.

(Male FGD)

Tight vaginas were also thought to create the impression that the woman "did not have sex carelessly, with many men". A woman could apply lemon juice prior to sex in order to show fidelity to her partner (ethnographic research and OEI with bar worker) or to give the impression of virginity (FGD with food and local beer vendors).

Some women thought that such practices could increase the risk of HIV infection:

They say if you have sex without friction you are unlikely to get AIDS, but it you insert things to reduce wetness, it can become a bit dry. This is the reason you find that those who [have sex] with friction are easily infected.

(FGD with bar and guesthouse/hotel workers)

Cloth could also be used intravaginally prior to sex to dry the vagina and increase tightness or friction during intercourse (ethnographic research).

Other inserts occasionally used to enhance sexual sensation included:

- Mashed onions applied to the penis (FGDs with males and food/local beer vendors)

- Vicks Vaporub or oil (unspecified) applied to male or female genitalia (both male FGDs, one FGD with bar and guesthouse/hotel workers and one FGD with food and local beer vendors)

- A solution of $s h a b u$, a white powder used for purifying drinking water applied to the vagina to tighten it (OEI with a local brew vendor, one FGD with bar/guesthouse workers and one FGD with food/local beer vendors)

- Elastic plant sap, herbal solutions, saliva and petroleum jelly for lubrication (two FGDs with bar and guesthouse workers and one FGD with food and local beer vendors).

In focus group discussions, practices to increase lubrication were mentioned less frequently than those to narrow the vagina or stimulate the penis. Lubrication was seen as something that may be desired by women to avoid soreness or injury or increase pleasure during sex.

\section{Discussion}

Among women working in food and recreational facilities in Mwanza, it was found that strong social norms underpinned practices to maintain vaginal hygiene, especially following sexual intercourse and during menstruation. Intravaginal cleansing by inserting fingers and either water alone or soap and water was thought necessary to remove "uchafu" (dirt), referring to vaginal secretions including post-coital discharge. Cloths were also, but less commonly, used intra- and extra-vaginally to clean and dry the 
genitalia before or after sex and to soak up menstrual blood. IVP to enhance sexual pleasure appeared less common than cleansing practices for hygiene. Prevalence of some intravaginal and menstrual practices differed significantly according to a number of socio-demographic and behavioural variables, and qualitative research also revealed the importance of environmental and relationship factors.

Our findings on IVP echo others from sub-Saharan Africa. Finger-cleansing and wiping have been shown to be very common, with some vaginal secretions viewed as dirt [7, 26, 29, 30]. Among female sex workers in Kenya, 72\% reported regular vaginal cleansing, with water and soap most commonly used [31]. However, the picture on prevalence of vaginal cleansing across sub-Saharan Africa is unclear, due to variation in definitions and methods. For example, the term "douching" has been used in some studies, but there is little or no evidence from these studies (or our own) that women use pressurized water to cleanse inside the vagina. This has led to efforts to develop standardised methods for IVP research [10, 11].

Evidence on IVP to enhance sexual pleasure is variable. The insertion of substances to dry and tighten the vagina appears to be common according to some studies in Southern Africa [30, 32, 33], notably with sex workers [34]. However, general population studies with larger sample sizes have shown lower prevalence [35-37], and an international qualitative study noted that motivations include vaginal tightening and removal of excess moisture rather than simply drying [11]. In our study intravaginal sexual enhancement practices were uncommon, but the use of lemon juice gives cause for concern. Studies have shown evidence of cervical abrasions and cell damage caused by intravaginal use of lemon juice, potentially increasing HIV risk [38-40].

Very few studies have examined menstrual protection practices in Africa. A small study in Zimbabwe $(n=43)$ showed that cotton wool was the most common commercial menstrual protection method used in the past year, followed by pads. Cloths or rags were the most common home products, used by $70 \%$ [41]. In our larger study, over three months, pads were less commonly used while cloths or towelling were also used by the majority. The participants in the Zimbabwe study expressed concern, as in our study, about hygiene when reusing cloths and rags without the facilities to wash and dry them properly. In our study, we also found that cloths were used to wipe, dry and clean the external and internal genitalia before and after sex. Our feasibility study showed that the use of cloth for vaginal cleansing was associated with higher HIV prevalence, controlling for other factors [42]. Higher HIV prevalence might be explained by potential for micro-abrasions or bacterial infection from intravaginal use of cloth in circumstances of poverty [9] where it is difficult to sterilise the cloth. Further research would aid in understanding the extent to which cloths are repeatedly used intravaginally, and ways in which they are washed and stored.

Sex during menstruation has not generally been considered in intravaginal practices research, though there is evidence that it may increase risk of STI [43, 44]. Our data show that menstrual blood was viewed as "dirt" and that sex during menstruation should therefore be avoided, sentiments echoed by study participants in Zimbabwe [41]. Menstrual beliefs and practices warrant more attention both with regard to HIV risk and microbicide development.

Our findings suggest that intravaginal and menstrual practices may in some instances be out of a woman's control. Indicators of mobility (spending time away from home) were positively associated with sex during menstruation and negatively associated with vaginal cleansing, suggesting that there was less control over these behaviours while travelling. This appears to be in keeping with qualitative findings concerning environmental influences such as access to water and ability to keep one's sexual activities private. The more settled living conditions likely to pertain among women in long-term relationships may explain the finding that vaginal cleansing was more likely among women who reported they were married than those who reported other relationship types. This was confirmed in that spending a night away from home was less likely among married women. Thus, though qualitative research showed that women in long-term relationships were not expected to cleanse the vagina after sex every time, their ability actually to do so seems to have been better than for women in other relationship types. Forced sex was associated with sex during menstruation, confirming the importance of lack of control.

\section{Findings with Implications for Microbicide} Acceptability and Adherence

Our findings demonstrate deep-seated norms of cleanliness supporting vaginal cleansing. This suggests that acceptability of and adherence to a microbicide or placebo gel product may be affected by the extent to which the product is believed to contribute to the cleanliness of the vagina, vaginal discharge, and avoidance of reproductive tract infections, and such beliefs should be studied during trials. Since menstrual blood was one of the fluids that should be actively removed from the vagina in order to promote health, menstrual beliefs and practices should be considered as important factors that may affect acceptability and adherence. Microbicides should be developed that will not be perceived to augment the amount of vaginal fluid or to contribute to infection by combining with menstrual blood. Findings on sexual enhancement practices suggest that attitudes to the lubricating properties of some microbicides 
should be studied during trials (as was done in the MDP301 trial [45]), with attention paid to how these vary according to type and number of partners [11, 17]. Variations in practices by socio-demographic and behavioural factors suggest that careful market research and niche marketing is likely to be necessary to optimise take-up and adherence to the new technology.

Findings with Implications for the Effectiveness of Microbicides

Though necessarily speculative in the absence of microbicide trial findings on HIV incidence, our findings do point to a number of areas of potential concern. With regard to microbicide trials, the most important implication is that microbicide efficacy may be undermined if IVP reduce the effectiveness of a microbicide in preventing HIV transmission. In our study, vaginal cleansing gives the greatest cause for concern because it was the most common IVP and was strongly supported by social norms, and it has potential to remove or dilute microbicide gel in sex acts unprotected by condoms (72\% of sex acts in our study: Fig. 1). In our study close to half of sex acts were followed by cleansing within 2 hours. In trials the effects of vaginal cleansing may vary, depending on the characteristics of the microbicide product itself. Microbicides under development have varying periods of activity against HIV and some are administered in a cervical ring rather than gel [46]. As noted above in discussion of the use of lemon juice and cloths, the practices outlined in this paper may also disturb the vaginal environment, altering susceptibility to HIV infection.

Limitations of this study include that it did not involve the use of microbicide or placebo gel, and thus was not directly a study of acceptability of or adherence to a particular product, and thus it was not possible to directly evaluate the effects of intravaginal practices on use of a microbicide product. The objective here, rather, was to provide rich contextual data that could eventually aid the interpretation both of a planned acceptability study involving the trial products and of trial results on effectiveness. The second limitation is that research participants were not representative of the general population. Rather, they were in a group that is important in the epidemiology of HIV in East Africa due to high-risk sexual behaviour associated with poverty, mobility and other factors [25, 26]. As usual in clinical trial recruitment, participants in enrolment interviews (and therefore in the coital diary study and OEIs) were volunteers and were not randomly selected from the estimated 2,494 women working in FRF in Mwanza at the time. Participants in ethnographic research and FGDs were not restricted to trial participants, but the use of purposive sampling methods limits the ability to generalise. However, the use of multiple research methods enabled triangulation and there was remarkable consistency in results across methods.

\section{Conclusion}

In circumstances where intravaginal and menstrual practices have the potential to alter trial results via their direct physical effects or via their associations with acceptability and adherence, efforts may be made to develop counselling methods to modify these practices. These methods should be contextually appropriate, based on "thorough understanding of the norms and beliefs surrounding the use of IVP" (McClelland: 272 [5]). This study has attempted to develop such an understanding in a population of female FRF workers in Mwanza. Findings on the prevalence of vaginal cleansing and its social importance suggest that in this context it may be difficult to persuade many women to abandon vaginal cleansing for the duration of a microbicide trial. However, qualitative research showed that timing of cleansing was variable and circumstantial, suggesting that it may be possible to encourage women to delay vaginal cleansing for a few hours after sex. Our findings also suggest that socio-demographic factors and living environments should be taken into account while developing counselling messages. However, the complex combination of norms, social characteristics and behavioural practices associated with IVP are likely to present challenges to the design of counselling. This underscores the importance of developing systems to measure and monitor these practices during trials and assess their impact during analyses of trial results [7]. Coital diaries may be employed to record frequencies of practices [22], and ethnographic research and FGDs to reveal the range and details of practices; how, why, and under which circumstances they are carried out, and the norms underlying them. These methods have been used in the recently completed MDP clinical trial in Mwanza [45].

Acknowledgements We would like to thank the participants in the study, and other members of the data collection team, Gilbert Bugeke and Kija Nyali. Financial support for the Microbicides Development Programme was provided by the UK Department for International Develeopment and the UK Medical Research Council. We are grateful to John Changalucha of the National Institute for Medical Research, Tanzania and Daniel Wight of the Medical Research Council, UK for institutional support, and to Ian Hambleton of the University of the West Indies for comments on data analysis. Permission to publish this study was granted by the National AIDS Control Programme, Tanzania. Financial support for the Microbicides Development Programme was provided by the UK Department for International Development and the UK Medical Research Council. 
Open Access This article is distributed under the terms of the Creative Commons Attribution Noncommercial License which permits any noncommercial use, distribution, and reproduction in any medium, provided the original author(s) and source are credited.

\section{References}

1. Brown JE, Brown RC. Traditional intravaginal practices and the heterosexual transmission of disease: a review. Sex Transm Dis. 2000;27(4):183-7.

2. Gresenguet G, Kreiss JK, Chapko MK, Hillier SL, Weiss NS. HIV infection and vaginal douching in Central Africa. AIDS. 1996;11:101-16.

3. Myer L, Denny L, de Souza M, Wright TC Jr, Kuhn L. Distinguishing the temporal association between women's intravaginal practices and risk of human immunodeficiency virus infection: a prospective study of South African women. Am J Epidemiol. 2006;163(6):552-60.

4. Myer L, Kuhn L, Stein ZA, Wright TC Jr, Denny L. Intravaginal practices, bacterial vaginosis, and women's susceptibility to HIV infection: epidemiological evidence and biological mechanisms. Lancet Inf Dis. 2005;5(12):786-94.

5. McClelland RS, Lavreys L, Hassan W, Mandaliya K, NdinyaAchola JO, Baeten JM. Vaginal washing and increased risk of HIV-1 acquisition among African women: a 10-year prospective study. AIDS. 2006;20(2):269-73.

6. van de Wijgert JHHM, Morrison CS, Cornelisse PGA, et al. Bacterial vaginosis and vaginal yeast, but not vaginal cleansing, increase HIV-1 acquisition in African women. J Acquir Immune Defic Syndr. 2008;48(2):203-10.

7. Braunstein $S$, van de Wijgert J. Preferences and practices related to vaginal lubrication: implications for microbicide acceptability and clinical testing. J Womens Health. 2005;14(5):424-33.

8. Mantell JE, Myer L, Carballo-Dieguez A, et al. Microbicide acceptability research: current approaches and future directions. Soc Sci Med. 2005;60(2):319-30.

9. Lees S, Desmond N, Allen C, Bugeke G, Vallely A, Ross D. Sexual risk behaviour for women working in recreational venues in Mwanza, Tanzania: considerations for the acceptability and use of vaginal microbicide gels. Cult Health Sex. 2009;11(6): 581-95.

10. Martin Hilber A, Chersich M, Van de Wijgert J, Rees H, Temmerman M. Vaginal practices, microbicides and HIV: what do we need to know? Sex Transm Infect. 2007;83:505-8.

11. Martin Hilber A, Hull T, Preston-Whyte E, et al. A cross cultural study of vaginal practices and sexuality: implications for sexual health. Soc Sci Med. 2010;70(3):392-400.

12. Weiss H, Wasserheit J, Barnabas R, Hayes R, Abu-Raddad L. Persisting with prevention: the importance of adherence for HIV prevention. Emerg Themes Epidemiol. 2008;5(1):8.

13. UNAIDS. Report on the global AIDS epidemic. Geneva: Joint United Nations Programme on HIV/AIDS; 2008.

14. Heise LL, Elias C. Transforming AIDS prevention to meet women's needs: a focus on developing countries. Soc Sci Med. 1995;40(7):931-43.

15. Orner P, Harries J, Cooper D, et al. Challenges to microbicide introduction in South Africa. Soc Sci Med. 2006;63(4):968-78.

16. Salter M, Go V, Celentano D, Diener-West M, Nkhoma C, Kumwenda N. The role of men in women's acceptance of an intravaginal gel in a randomized clinical trial in Blantyre, Malawi: a qualitative and quantitative analysis. AIDS Care. 2008;20(7):853-62.
17. Montgomery C, Lees S, Stadler J, Morar N, Ssali A, Mwanza B. The role of partnership dynamics in determining the acceptability of condoms and microbicides. AIDS Care. 2008;20(6):733-40.

18. Koo HP, Woodsong C, Dalberth BT, Viswanathan M, SimonsRudolph A. Context of acceptability of topical microbicides: sexual relationships. J Soc Issues. 2005;61(1):67-93.

19. Stirratt MJ, Gordon CM. Adherence to biomedical HIV prevention methods: considerations drawn from HIV treatment adherence research. Curr HIV/AIDS reports. 2008;5(4):186-92.

20. Padian N, Buvé A, Balkus J, Serwadda D, Cates WJ. Biomedical interventions to prevent HIV infection: evidence, challenges, and way forward. Lancet. 2008;372(9638):585-99.

21. Turner A, Van Damme K, Jamieson D, Khan M, Pettifor A, Swezey T. Predictors of adherent use of diaphragms and microbicide gel in a four-arm, randomized pilot study among female sex workers in Madagascar. Sex Transm Dis. 2009;36:249-57.

22. Allen CF, Lees SS, Desmond N, et al. Validity of coital diaries in a feasibility study for the microbicides development programme trial among women at high risk of HIV/AIDS in Mwanza, Tanzania. Sex Transm Infect. 2007;83:490-7.

23. Van de Wijgert J, Morrison C, Salata R, Padian N. Is vaginal washing associated with increased risk of HIV infection? AIDS. 2006;20(9):1347-8.

24. Desmond N, Allen CF, Clift S, et al. A typology of groups at risk of HIV/STI in a gold mining town in north-western Tanzania. Soc Sci Med. 2005;60(8):1739-49.

25. Kapiga SH, Sam NE, Shao JF, et al. HIV-1 epidemic among female bar and hotel workers in northern Tanzania: risk factors and opportunities for prevention. J Acquir Immune Defic Syndr. 2002;29(4):409-17.

26. Watson-Jones D, Weiss HA, Rusizoka M, et al. Risk factors for Herpes simplex virus type 2 and HIV among women at high risk in Northwestern Tanzania: preparing for an HSV-2 intervention trial. J Acquir Immune Defic Syndr. 2007;46(5):631-42.

27. Vallely A, Kasindi S, Hambleton IR, et al. Microbicides development program, Tanzania. Baseline characteristics of an occupational cohort and reattendance at 3 months. Sex Transm Dis. 2007;34(9):638-43.

28. Association of Social Anthropologists. Ethical guidelines for good research practice. Association of Social Anthropologists of the UK and Commonwealth. http://www.theasa.org/ethics/ guidelines.htm (2008).

29. Van De Wijgert J, Mbizvo M, Dube S, Mwale M, Nyamapfeni P, Padian N. Intravaginal practises in Zimbabwe: which women engage in them and why? Cult Health Sex. 2001;3(2):133-48.

30. Runganga A, Kasule J. The vaginal use of herbs/substances: an HIV transmission facilitatory factor? AIDS Care. 1995;7:639-45.

31. Fonck K, Kaul R, Keli F, et al. Sexually transmitted infections and vaginal douching in a population of female sex workers in Nairobi, Kenya. Sex transm infect. 2001;77(4):271-5.

32. Beksinska ME, Rees H, Kleinschmidt I, McIntyre J. The practice and prevalence of dry sex among men and women in South Africa: a risk factor for sexually transmitted infections? Sex transm infect. 1999;75:178-80.

33. Civic D, Wilson D. Dry sex in Zimbabwe and implications for condom use. Soc Sci Med. 1996;42(1):91-8.

34. Morar NS, Ramjee G, Gouws E, Wilkinson D. Vaginal douching and vaginal substance use among sex workers in KwaZulu-Natal, South Africa. S Afr J Sci. 2003;99(7-8):371-4.

35. Myer L, Denny L, De Souza M, Barone MA, Wright TC, Kuhn L. Intravaginal practices, HIV and other sexually transmitted diseases among South African women. Sex Transm Dis. 2004;31(3): 174-9.

36. Dallabetta GA, Miotti PG, Chiphangwi JD, Liomba G, Canner JK, Saah AJ. Traditional vaginal agents-use and association 
with HIV-infection in Malawian women. AIDS. 1995;9(3): 293-7.

37. Orubuloye I, Caldwell P, Caldwell J. A note on suspect practices during the AIDS epidemic: vaginal drying and scarification in southwest Nigeria. Health Transit Rev. 1995;5(suppl.):161-5.

38. Global Campaign for Microbicides. Why women should NOT use lemon or lime juice as a microbicide. http://wwwglobalcampaignorg/clientfiles/NEW\%201emon-lime\%20juice_June26 doc (2006).

39. Lackman-Smith C, Snyder BA, Luckenbaugh KM, et al., editors. Preclinical evaluations of lemon and lime juice as microbicide candidates. Microbicides 2006. Cape Town, South Africa; 2006.

40. Fletcher P, Harman S, Shattock R, Boothe A, Doncel G. Preclinical evaluation of lime juice as a topical microbicide candidate. Retrovirology. 2008;5(3).

41. Averbach S, Sahin-Hodoglugil N, Musara P, Chipato T, van der Straten A. Duet ${ }^{\circledR}$ for menstrual protection: a feasibility study in Zimbabwe. Contraception. 2009;79:463-8.
42. Francis $\mathrm{S}$, Allen $\mathrm{C}$, Vallely A, et al. Intravaginal practices in a microbicide feasibility study in Mwanza, Tanzania: baseline associations with bacterial vaginosis, sexually transmitted infections and HIV. In: 17th Conference of the international society for STD Research. Seattle, USA; 2007 July 29-August 1.

43. Shah R, Bradbeer C. Women and HIV-revisited ten years on. Int J STD AIDS. 2000;11(5):277-83.

44. Tanfer K, Aral SO. Sexual intercourse during menstruation and self-reported sexually transmitted disease history among women. Sex Transm Dis. 1996;23(5):395-401.

45. Montgomery CM, Gafos M, Lees S, et al. Re-framing microbicide acceptability: findings from the MDP301 trial. Cult Health Sex. 2010;12(6):649-62.

46. Romano J, editor. Characterization of in vitro release and in vivo delivery of TMC120 with an intravaginal ring. In: International AIDS Conference, Toronto; 2006. 